\title{
Perventricular and Percutaneous Closure of Traumatic Ventricular Septal Defects Following Blunt Chest Trauma
}

\author{
Karim A. Diab, MD, FACC ${ }^{*}$, Kamel Shibbani, MD², John Nigro, MD³, Stephen Pophal, MD², \\ Ernerio T. Alboliras, MD, FACC ${ }^{4}$ \\ ${ }^{1}$ Department of Pediatric Cardiology, Rush University Medical Center, Chicago, Illinois, USA \\ ${ }^{2}$ Lieber Institute for Brain Development, Johns Hopkins University, Baltimore, Maryland, USA \\ ${ }^{3}$ Department of Pediatric Cardiology, Phoenix Children's Hospital, Phoenix, Arizona, USA \\ ${ }^{4}$ Department of Pediatric Cardiology, Banner Children's Hospital, Mesa, Arizona, USA
}

\begin{abstract}
Traumatic ventricular septal defects (VSDs) are very rare and can result from either penetrating or blunt chest trauma. They can lead to significant hemodynamic changes and heart failure and can be challenging to manage. We present two patients with muscular VSDs resulting from nonpenetrating trauma to the chest in whom Amplatzer Muscular VSD Occluders were successfully used for defect closure via percutaneous and periventricular approaches.

Copyright $\odot 2016$ Science International Corp.
\end{abstract}

\section{Key Words}

Traumatic ventricular septal defect •

Percutaneous closure - Perventricular closure • Blunt chest trauma - Post-infarct Amplatzer VSD occluder

\section{Introduction}

Blunt trauma to the chest usually results from highspeed motor vehicle accidents and can cause significant cardiac injury including ventricular septal defects (VSDs) [1]. These defects can be asymptomatic but can also result in life-threatening hemodynamic effects. This report describes two cases of traumatic VSDs resulting from blunt chest trauma that were successfully managed by percutaneous and periventricular device closure.

\section{Case Series}

\section{First Case}

A 19-year-old male involved in an automobile collision was admitted to the intensive care unit in shock with hypotension and pneumothorax. After resuscitation, he continued to have significant pulmonary ede$\mathrm{ma}$ and elevated troponin I at $27.99 \mathrm{ng} / \mathrm{mL}$. An electrocardiogram (ECG) showed sinus rhythm with ST elevation in the inferior leads. An echocardiogram revealed an apical muscular VSD measuring 6-8 $\mathrm{mm}$ with left-to-right shunting, a transventricular pressure gradient of $55 \mathrm{~mm} \mathrm{Hg}$, mild mitral regurgitation, normal systolic function biventricularly, and no effusions (Figure 1).

Cardiac MRI showed an VSD and a focal area of thinning of the mid left lateral ventricular septal wall. Cardiac catheterization revealed a Qp:Qs of 2:1 with a (c) 2016 Journal of Structural Heart Disease Published by Science International Corp. ISSN 2326-4004

Accessible online at: http://structuralheartdisease.org/
* Corresponding Author:

Karim A. Diab MD FACC

Department of Pediatric Cardiology,

Rush University Medical Center

1653 W. Congress Parkway, Chicago, IL 60612, USA

Tel: +1 312942 6800, Fax: +1 312942 6801; E-Mail: Karim_Diab@rush.edu 

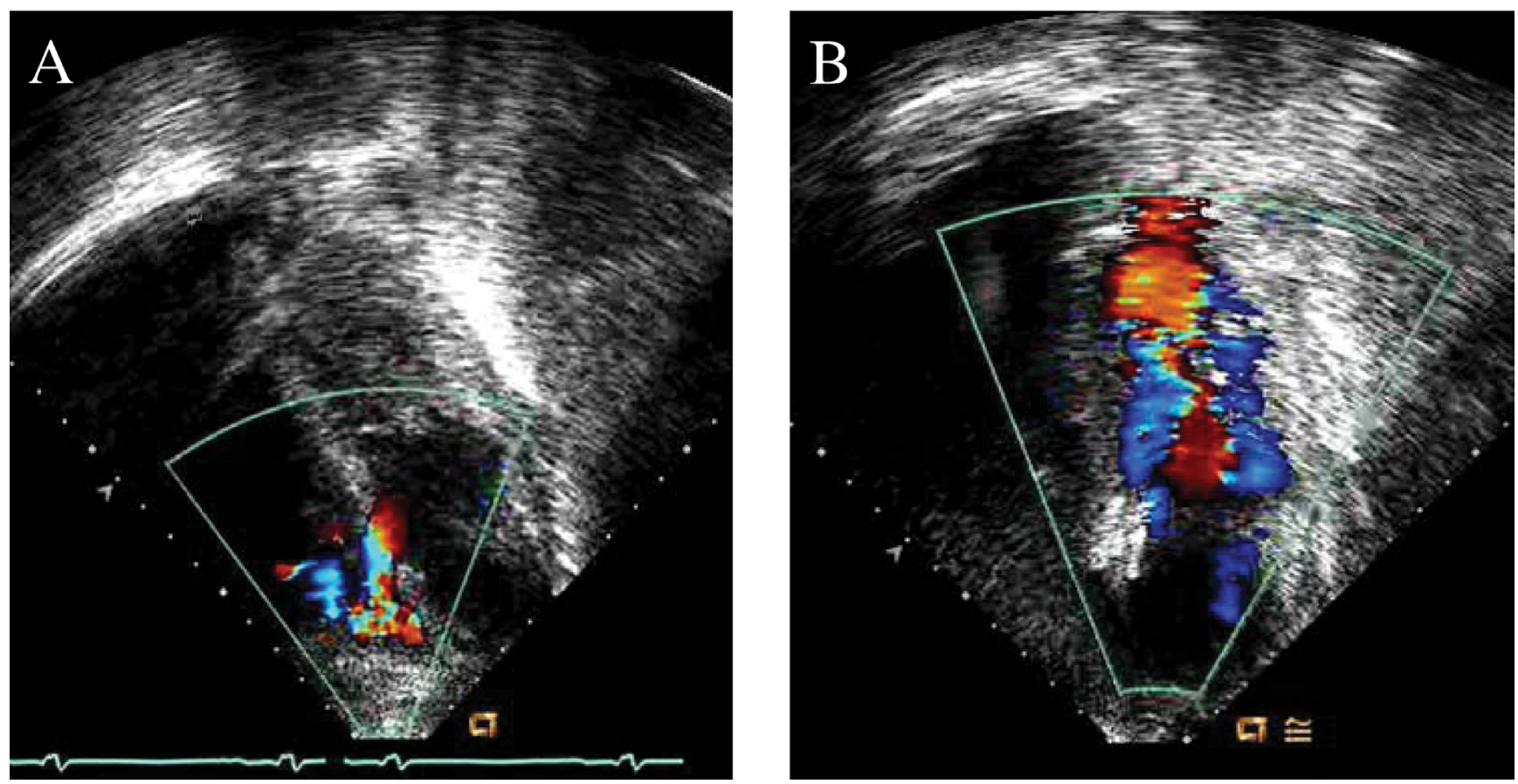

Figure 1. (Panels $A, B$ ). Transthoracic echocardiogram views before (Panel A) and after (Panel B) closure of the defect showing a posterior-apical muscular ventricular septal defect (VSD) that was successfully closed with a $12 \mathrm{~mm}$ Amplatzer muscular VSD device.

right ventricular (RV) pressure of $42 / 7 \mathrm{~mm} \mathrm{Hg}$, pulmonary artery pressure of $41 / 17 \mathrm{~mm} \mathrm{Hg}$, and normal pulmonary vasculature resistance. Transesophageal echocardiogram (TEE) showed a posterior-apical muscular VSD measuring $10 \mathrm{~mm}$ with left-to-right shunting. Angiography demonstrated a significant VSD measuring about $8 \mathrm{~mm}$ at its narrowest point. After the VSD was crossed and an arteriovenous loop was established, a $12 \mathrm{~mm}$ Amplatzer muscular VSD device (AGA/St. Jude Medical Corporation, St. Paul, $M N$ ) was successfully deployed that left only minimal residual shunting seen on TEE. The patient did well post-closure and was extubated and eventually discharged home. A follow-up echocardiogram 1.5 years later revealed a tiny residual shunt.

\section{Second Case}

A 31-year-old male involved in a motorcycle accident was hospitalized in a severe state of shock due to large hemothorax, tamponade, abdominal compartment syndrome, and multiple skeletal fractures. He underwent emergent exploratory laparotomy, thoracotomy, and pericardiotomy. Postoperatively, he continued to require ventilatory support and subsequently developed pulmonary embolism. ECG revealed sinus tachycardia and incomplete right bundle branch block. An echocardiogram revealed an avulsed tricuspid valve with severe regurgitation, as well as a large apical muscular VSD measuring about $18 \mathrm{~mm}$ in diameter, mild pulmonary hypertension, and normal left ventricular (LV) systolic function. Cardiac catheterization showed a Qp:Qs of 2.4:1. As the patient required repair of the tricuspid valve and VSD closure, he was taken to the operating room for periventricular hybrid closure of the VSD followed by tricuspid valve repair.

After median sternotomy, TEE-guided needle puncture through the lower inferior RV surface created access for insertion of a delivery sheath and subsequent closure of the defect with an $18 \mathrm{~mm}$ Amplatzer Postinfarct Muscular VSD Occluder (Figure 2).

The device was deployed, and TEE showed only a small residual shunt. This was followed by tricuspid valve repair on cardiopulmonary bypass using an annuloplasty band. The patient was discharged from the hospital 4 days after VSD closure. A follow-up 

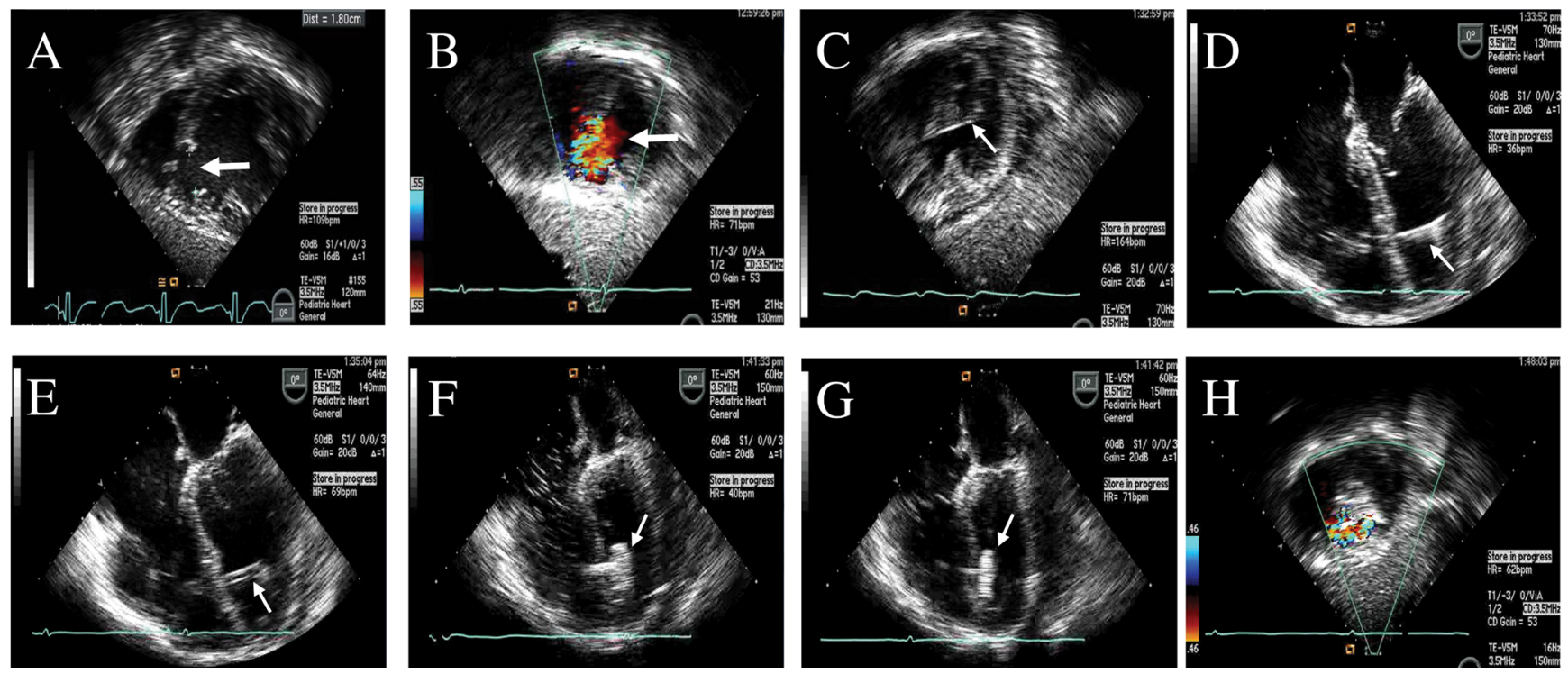

Figure 2. TEE images during hybrid or periventricular device closure of a traumatic muscular ventricular septal defect (VSD). (Panels $A, B$ ). Transesophageal echocardiogram (TEE) images without and with color Doppler demonstrating the defect in the muscular septum (arrows). (Panels C, D). TEE images during passage of the guide wire (arrow) across the VSD and into the left ventricle (LV) following needle puncture of the right ventricular free wall. (Panels E). Passage of the delivery sheath into the LV cavity (arrow). (Panels F) Deployment of the LV disk of the $18 \mathrm{~mm}$ Amplatzer Postinfarct Muscular VSD Occluder (arrow) in the LV cavity and then (Panels G), aligned to the ventricular septum (arrow). (Panels $\mathrm{H}$ ). Image taken after device release demonstrating good device position with the right and left disks in their respective position and a small residual shunt.

echocardiogram after 6 months showed a small residual VSD and mild tricuspid regurgitation, absence of pulmonary hypertension, and normal global ventricular systolic function.

\section{Discussion}

An acute onset left-to-right cardiac shunt after a blunt chest trauma results mostly from acquired VSD [1-6]. These traumatic VSDs most commonly involve the muscular portion of the septum, particularly the apical portion due to its thin structure [1, 3-7]. The mechanisms include anteroposterior compression of the heart between the sternum and spine secondary to high intrathoracic pressures at impact and myocardial infarction from rapid deceleration causing coronary damage $[1,3]$. Trauma can result in damage to the valves or rupture of the septum that can occur immediately or be delayed for several days [4].

Patients with traumatic VSDs can be asymptomatic or present with fulminant acute cardiogenic shock. Elevated troponin levels or ST-segment elevation with no wall-motion abnormalities should increase our suspicion for traumatic VSD after blunt trauma to the chest, as was the case in our first patient.

Traumatic VSD management depends on the size of the defect, the degree of shunting, and the presence of heart failure [8]. A conservative approach is usually recommended for asymptomatic small traumatic VSDs as these defects might close spontaneously $[1,8]$. On the other hand, indications to close these defects include Qp:Qs >2:1, hemodynamic instability, the presence of pulmonary hypertension, and left-sided chamber dilatation. Closure can be accomplished either surgically through a right ventriculotomy or using a percutaneous approach $[5,7,8]$. In patients with a low left-to-right shunt and mild heart failure, medical treatment can be attempted first for 2 to 3 weeks followed by repair once the myocardial tissue surrounding the VSD shows signs of fibrous ring formation $[3,6]$. Device closure can then be performed using either the percutaneous or hybrid/periventricular approach. The latter was helpful in our case as the patient also 
required tricuspid valve repair. The use of device closure in this case was also helpful as closure of apical muscular VSDs can be surgically challenging.

Different devices have been used for traumatic VSD closure depending on the defect size and configuration. ASD occluder devices have been associated with hemolysis because of their wire mesh configuration and cloth barrier not being designed for the high-pressure ventricular system [5]. Hence, it is preferable to use the postinfarct Amplatzer VSD Occluder for large traumatic VSDs, as was the case in our second patient.

In conclusion, cardiac injury, particularly valvular rupture and VSDs, should always be considered in all cases of trauma to the chest whether penetrating or blunt. Percutaneous device closure of these defects is effective and can help avoid surgical repair in these high-risk patients. Hybrid or periventricular closure is an alternative to percutaneous closure in those who need additional intracardiac repair of associated lesions.

\section{Conflict of Interest}

The authors have no conflict of interest relevant to this publication.

\section{Comment on this Article or Ask a Question}

\section{References}

1. Genoni M, Jenni $R$, Turina M. Traumatic ventricular septal defect. Heart. 1997;78:316318. DOI: $10.1136 /$ hrt.78.3.316

2. Pruitt $C M$, Titus MO. Ventricular septal defect secondary to a unique mechanism of blunt trauma: a case report. Pediatr Emerg Care. 2007;23:31-32. DOI: 10.1097/ PEC.0b013e31802c61c3

3. Muyskens S, Lasala J, Balzer D. Percutaneous closure of a complex posttraumatic muscular ventricular septal defect. Catheter Cardiovasc Interv. 2008;72:408-412. DOI: $10.1002 / c c d .21659$

4. Kadner A, Fasnacht M, Kretschmar O, Prêtre R. Traumatic free wall and ventricular septal rupture - 'hybrid' management in a child. Eur J Cardiothorac Surg. 2007;31:949-951. DOI: 10.1016/j.ejcts.2007.01.068
5. Suh WM, Kern MJ. Transcatheter closure of a traumatic VSD in an adult requiring an ASD occluder device. Catheter Cardiovasc Interv. 2009;74:1120-1125. DOI: 10.1002/ ccd. 22141

6. Terui G, Kaneko K, Miura M, Kawazoe K. Ventricular septal defect secondary to non-penetrating chest trauma. Jpn Circ J. 1997;61:951-953. DOI: 10.1253/ jcj.61.951

7. Jeon $\mathrm{K}$, Lim WH, Kang $\mathrm{SH}$, Cho I, Kim $\mathrm{KH}$, Kim HK, et al. Delayed diagnosis of traumatic ventricular septal defect in penetrating chest injury: small evidence on echocardiography makes big difference. J Cardiovasc Ultrasound. 2010;18:28-30. DOI: 10.4250/ jcu.2010.18.1.28
8. Pesenti-Rossi D, Godart F, Dubar A, Rey C. Transcatheter closure of traumatic ventricular septal defect: an alternative to surgery. Chest. 2003;123:2144-2145. DOI: 10.1378/chest.123.6.2144

Cite this article as: Diab KA, Shibbani K, Nigro J, Pophal S, Alboliras ET. Perventricular and Percutaneous Closure of Traumatic Ventricular Septal Defects Following Blunt Chest Trauma. Structural Heart Disease. 2016;2(4):98-101. DOI: http://dx.doi. org/10.12945/j.jshd.2015.007.15 